\title{
Impact of Choppies Enterprise in Southern Africa: An Exploratory Study on Strategic Management Perspective
}

\author{
Taelo Simon \\ Post Graduate Researcher \\ School of Economics and Business Administration \\ Chongqing University, China \\ E-mail:simontaelo@outlook.com \\ Abdur Rakib Nayeem \\ Lecturer \\ Department of Business Administration \\ Times University Bangladesh, Bangladesh \\ $\&$ \\ Doctoral Scholar \\ School of Economics and Business Administration \\ Chongqing University, China \\ Email:11900120@cqu.edu.cn \\ Md. Khorshed Alam \\ Post Graduate Researcher \\ Software Engineering \\ School of Big Data and Software Engineering \\ Chongqing University, China \\ Email:khorshedalam49@gmail.com \\ Md. Shahab Ali Raja \\ Lecturer \\ Department of Business Administration \\ University of Kotliazad Jammu and Kashmir, Pakistan \\ Email: shahabali48@hotmail.com
}

\begin{abstract}
Organizations nowadays are increasingly impacting in using strategic management to improve their performance; this study has mainly focused on the impact of strategic management on the performance of Choppies Enterprises. Choppies Enterprise Botswana-based Choppies is an investment holding company operating in the retail sector across sub-Saharan Africa. Its operations are food and general merchandise retailing as well as financial services transactions supported by centralized distribution channels, through distribution centers and logistical support assets in Botswana, South Africa, Zimbabwe, Kenya, and Zambia. This study focused on the strategic management of Choppies Enterprises. The main research problem was to make an in-depth analysis of its competitive strategy and how to implement it. The main research method was qualitative research by analyzing their company data, annual reports, and making interviews with the manager, staff, and customers in Botswana shops. The result shows a clear image of the process of strategic management by Choppies' case. Some recommendations made for Choppies help to improve their sustainable developments and support a vivid example for many companies. In the theoretical part, it described the definition, process, benefit, and challenge of strategic management. In the practical part, an exhaustive analysis of the company's strengths, weaknesses, opportunities, and threats was made by using the detailed figures.
\end{abstract}

Keywords: Strategic Management, Business Performance, Competitive Advantage, Choppies, Enterprises. 


\section{Introduction}

Strategic management practices can be used in bridging the performance gap experienced by a firm. Organizations apply strategic management practices in their operations which has a lot of influence on market conditions, employee knowledge, and diversification of production line. Their success rests upon effective strategic management practices. Strategic Management became the most important basic features in the success of any organization, projects or business, and it helps to build a base essential to develop and measure performance, Strategic Management is a System of integrated processes related to strategic analysis and emanating from the organization's vision, mission until reach to the organization goals in growth and continuity and get a competitive advantage. Small businesses are vital contributors to the health of the economy and diversity of opportunity in society. It is not only important for all businesses to understand why they are in business but also to put in practice a successful and suitable strategy to enhance business performance (Jofre, 20II). The online assumes an essential part in our life so individuals can chat with each other anyplace on the planet through the online-based transaction, they can send the email whenever, they can search for data on the web, they can play the amusement with Individuals over the world, and they can even purchase things on the web. As indicated by the exploration of the U.S. (Shaownet al., 2018). When it comes to customer service, this is probably one of the most important parts of your business. Suppose, it will know how the consumer's response to make the purchase decision of that product in case of having the awareness about the product (Nayeem et al., 2020). Without your customers coming back for more and more of your product, there is no way that you're going to be successful. That's why a high-quality customer service operation is crucial to the future of your company. This is because a strategy is a source of competitive advantage that has been used in recent years by different companies to gain competency over their rivalries. There has been an increased interest in the role of Small and Medium Enterprises in job creation and economic growth globally. Developing small and medium enterprises (SMEs) helps to achieve sustainable growth as a centralized theme. Enterprises play a vital role in the country's overall production networks and they are core to the economic growth of developing countries. The contributions of formal enterprises are 50\% of total employment and 33\% of the national income of emerging economies. Businesses need to hire employees. They create jobs and these economic opportunities uplift and support communities through increasing the quality of life and overall standard of living. When new businesses export goods and services to nearby regions, these enterprises contribute directly to a region's productivity and earnings. This increase in revenue strengthens an economy and promotes the overall welfare of a population. Choppies Enterprises Limited is one of the biggest supermarkets in Botswana and they operate a supermarket chain, which is engaged in providing consumer goods. The stores offer a wide variety of like fruits, vegetables, butchery, bakery, cosmetics, groceries, etc. It is a leading market retailer In Botswana with more than 200 stores countrywide.

\section{I.I Research Problem}

Choppies Enterprises have an important role to play in developing the economy of Botswana, not only in economic development but also in poverty alleviation and job creation. Even though this is the case most Choppies stores in Botswana fail within the first phase due to the lack of strategic management skills by those leading the organization.

\section{I.2 Objectives of Research}

The objective of the study was to establish strategic management practices and their influence on the performance of Choppies enterprises in Botswana and to explore competitive business strategies that can be adopted to develop and sustain the Enterprise sector in African countries.

\section{I.3 Significance of the Research}

The significance of the study is to analyze Choppies Enterprises in Botswana and advise them on strategic management for it to be competent. The study will be guided by the following research questions; How to take advantage of strategic management to facilitate the development of Choppies. The study will enable managers to understand the need for strategic management. The study will be of great value to the manager of companies to the managers and owners of Enterprises in making appropriate strategies for their firms to enhance competitive advantage and performance and will provide room for further research on improving adoption of strategic management practices in Botswana since it is amongst the first papers regarding this topic. The findings and recommendations of this research will not be useful only to Choppies Enterprises but to any other enterprise that needs to be competent to beat the market competition.

\section{I.4 Limitation of the Research}

There are some limitations to the process of data collection. Firstly, the exact figures of the sales situation are avoided in the interview. All of the analysis is concluded from the official website and annual reports. The answers from the interviewees are more general information therefore the recommendation cannot be made especially for the Choppies stores in the different selected areas of the research. Most of the common customers only have no clue of strategic management due to the abstractness of this topic, so it tends to be limited to the strategists and senior management level. 


\section{Literature Review}

A strategy is an integrated and coordinated set of commitments and actions designed to exploit core competencies and gain competitive advantage. Strategic competitiveness is achieved when a firm successfully formulates and implements a value-creating strategy. Kenneth Andrews defined strategy as "the pattern of major objectives, purposes or goals and essential policies or plans for achieving the goals, stated in such a way as to define what business the company is in or is to be in and the kind of company it is or is to be." This definition of strategy emphasizes on purpose and how the purpose will be achieved (Hitt et al., 20I2). It also emphasizes the values and the cultures that the company stands for. Kenichi Ohmae defines strategy as "how a corporation endeavors to differentiate itself positively from its competitors, using its relative strengths to better satisfy customer needs." Ohmae's definition highlights the competitive aspect of strategy and the strengths required to satisfy customer needs. According to the Library and Archives in southern Africa (2017), Choppies was born in 1986 in a Botswana Town called Lobatse. They sell groceries and general merchandise. The online assumes an essential part in our life so individuals can chat with each other anyplace on the planet through the online-based transaction, they can send the email whenever, they can search for data on the web, they can play the amusement with individuals over the world, and they can even purchase things on the web (Shaown et al., 2018). The first store was the Wayside supermarket. 1993 saw the opening of a second store still in Lobatse. From I993, Choppies embarked on a great expansion drive, with new stores being opened in the greater Gaborone periphery. Choppies became a listed company on the Botswana Stock Exchange on January 26 and is a constituent of the BSE Domestic Company Index with an approximate market capitalization of BWP2.4 billion as at 20 December 20I2. It was found to be an ideal point as we intend to supply to all stores within a $500 \mathrm{~km}$ radius. Of the significant developments that Choppies has been active in, 2014 saw the opening of a distribution Centre in Zimbabwe. Our foresight is to grow into East Africa, with an emphasis in Tanzania and Kenya. Choppies believes in the potential of the African market hence, especially in Muslim consumer's continued growth. This will probably help provide improved facts and information particularly in the Islamic Marketing research area (Nayeem, 2018). Only then we can apply the concept and see how those two can work together for business enlargement in the future (Nayeem et al., 2020).

\section{I Economic Impact on Botswana through Enterprises}

Botswana is one of Africa's landlocked countries, located in the south-west part of the continent. It is surrounded by four countries - Namibia to the west and north, South Africa to the south, Zimbabwe to the east, and shares a tiny section of its borders (about I56 meters or I7I yards) with Zambia in the northeast. The current population of Botswana is 2,324,492 as of Sunday, December 8, 2019, based on World meters elaboration of the latest United Nations data. Large firms normally tend to produce an elite number of high wage income earners whereas SMEs produce a significantly large number of relatively lowincome earners (Maramwidze-Merrison, 2019). The development of SMEs would, therefore, help spread income to more people. Since the majority of Batswana (Over $65 \%$ ) are living in rural areas, the promotion of the development of SMEs should continue to be a policy priority to narrow the gap between urban and rural development and to monitor social inequities and rural migration (Eriksson \& Kovalainen, 2008). The report says this is due to limited management skills, lack of access to markets, poor work ethics, excessive laws and regulations, lack of information on government assistance programs, lack of entrepreneurial "role models" and financial constraints though several measures have been proposed to address some of these constraints.

\subsection{Impact of Strategic Management Practice on Enterprises Performance}

Looking back in history, the basic benefit of strategic management has been helped organizations formulate sound strategies by using the more systematic, logical, and rational approach to strategic choice. Strategic management practices have been observed to significantly relate to the sustainability and growth of firms in the wake of modern corporate governance systems globally (Muriuki et al., 2017). Several studies related to strategic management and performance have been done in Kenya and internationally.

\subsection{Strategic Management and Challenges of Choppies}

The point of a strategy is a new vision. This is an opportunity to create a road map with broad buy-in and narrowed focus. There should be distinct milestones, a clear timeline, and precise roles for employees. If taking on a large, company-wide initiative, it is better to start small to ensure goals are manageable and achievable. From there, resources and objectives can be expanded until the result is achieved in the set timelines. While strategy implementation is about aligning different activities, it is also about creating commitment throughout the entire organization. Commitment is created when employees see where and how they can make a difference and are stimulated to take action within the boundaries set by the strategy. But it takes time to create an organizational context that stimulates widespread action-taking. All too often, managers do not take the time to create that context (Verweire, 2018). 


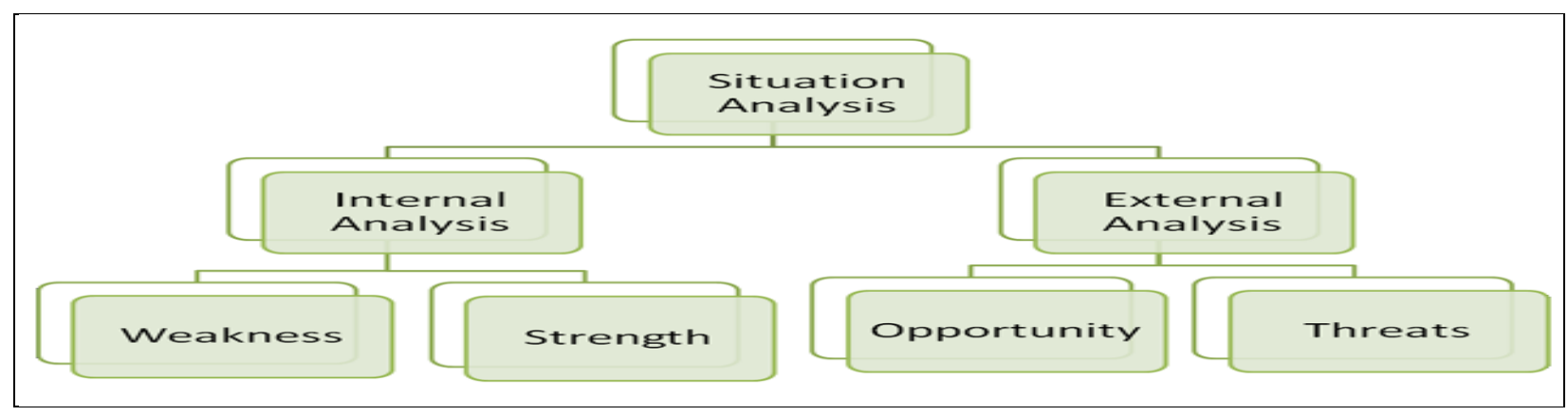

Figure I. An analysis of the external and internal environment of Choppies

The SWOT Analysis framework facilitates an organization to identify internal strategic factors such as -strengths and weaknesses, \& external strategic factors such as - opportunities and threats. It leads to a 2X2 matrix - also called SWOT Matrix.

\section{Choppies SWOT Analysis}

A SWOT analysis of Choppies involves the strengths, weaknesses; opportunities, as well as threats, which can be briefly shown in the table below.

\begin{tabular}{cc}
\hline $\begin{array}{c}\text { Strength } \\
\text { Low-cost prices } \\
\text { Strong brand image }\end{array}$ & $\begin{array}{c}\text { Weakness } \\
\text { Low quality } \\
\text { Opportunities }\end{array}$ \\
$\begin{array}{cc}\text { Scope to expand the business } \\
\text { International market penetration }\end{array}$ & Threats \\
\hline
\end{tabular}

\section{I Strengths of Choppies -Internal Strategic Factors}

- Good Returns on Capital Expenditure - Choppies Enterprises, is relatively successful at the execution of new projects and generated good returns on capital expenditure by building new revenue streams.

- Automation of activities brought consistency of quality to Choppies, products and has enabled the company to scale up and scale down based on the demand conditions in the market.

- Strong dealer community - It has built a culture among distributors \& dealers where the dealers not only promote the company's products but also invest in training the sales team to explain to the customer how he/she can extract the maximum benefits out of the products.

- Successful track record of integrating complimentary firms through mergers \& acquisitions. It has successfully integrated the number of technology companies in the past few years to streamline its operations and to build a reliable supply chain.

- Strong Brand Portfolio - Over the years Choppies has invested in building a strong brand portfolio. This brand portfolio can be extremely useful if the organization wants to expand into new product categories.

- High level of customer satisfaction - the company with its dedicated customer relationship management department has able to achieve a high level of customer satisfaction among present customers and good brand equity among potential customers.

\subsection{Weakness of Choppies - Internal Strategic Factors}

- The company has not been able to tackle the challenges present by the new entrants in the segment and has lost a small market share in the niche categories. Choppies has to build an internal feedback mechanism directly from the sales team on the ground to counter these challenges.

- Days inventory is high compare to the competitors - making the company raise more capital to invest in the channel. This can impact the long term growth of Choppies

- Investment in Research and Development is below the fastest growing players in the industry. Even though Choppies, is spending above the industry average on Research and Development, it has not been able to compete with the leading players in the industry in terms of innovation. It has come across as a mature firm looking forward to bring out products based on tested features in the market. 
- Not highly successful at integrating firms with different work cultures. As mentioned earlier even though Choppies is successful at integrating small companies it has its share of failure to merge firms that have different work cultures.

- There are gaps in the product range sold by the company. This lack of choice can give a new competitor a foothold in the market.

- Financial planning is not done properly and efficiently. The current asset ratio and liquid asset ratios suggest that the company can use the cash more efficiently than what it is doing at present.

- We need more investment in new technologies. Given the scale of expansion and different geographies the company is planning to expand into, Choppies needs to put more money in technology to integrate the processes across the board. Right now the investment in technologies is not at par with the vision of the company.

\subsection{Opportunities for Choppies - External Strategic Factors}

- Economic uptick and an increase in customer spending, after years of recession and slow growth rate in the industry, is an opportunity for Choppies, to capture new customers and increase its market share.

- The new technology provides an opportunity for Choppies to practices differentiated pricing strategy in the new market. It will enable the firm to maintain its loyal customers with great service and lure new customers through other value oriented propositions.

- New customers from online channels - Over the past few years, the company has invested a vast sum of money into the online platform. This investment has opened a new sales channel for Choppies In the next few years the company can leverage this opportunity by knowing its customer better and serving their needs using big data analytic.

- Lower inflation rate - The low inflation rate bring more stability in the market, enable credit at a lower interest rate to the customers of Choppies

\subsection{Threats are Choppies Faces - External Strategic Factors}

- The demand for highly profitable products is seasonal in nature and any unlikely event during the peak season may impact the profitability of the company in the short to medium term.

- New technologies developed by the competitor or market disrupt could be a serious threat to the industry in medium to long term future.

- The shortage of skilled workforce in a certain global market represents a threat to the steady growth of profits for Choppies in those markets.

- Changing consumer buying behavior from an online channel could be a threat to the existing physical infrastructure is a driven supply chain model.

- Growing strengths of local distributors also present a threat in some markets as the competition is paying higher margins to the local distributors.

\section{Brand Strategy}

Your brand is only as strong as the energy you put into it. Brand building and positioning require synchronized efforts of several moving parts to create a perception in the marketplace that drives your business forward. There are so many advantages to brand strategy including creating market differentiation, a sense of belonging to the company. Choppies supermarket retail offers include leading international food brands and fast-moving consumer goods (FMCG) products as well as Choppies' private label for value-minded consumers.
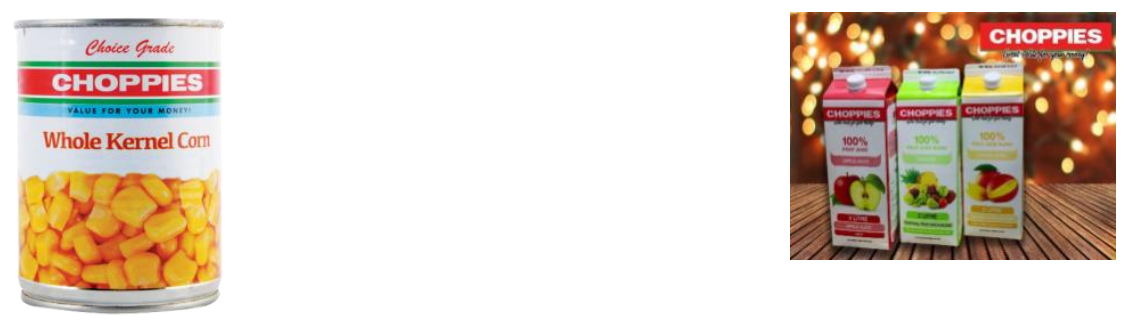

\section{Differentiation Strategy}

Defines differentiation strategy as to how you make your firm stand out from otherwise similar competitors in the marketplace. Usually, it involves highlighting a meaningful difference between you and your competitors. And that difference must be valued by your potential clients. A strong differentiated will provide a competitive advantage for your firm. So far, Choppies is the only retailer in Botswana that provides financial services. 


\section{Diversification}

Choppies has full supermarket offerings, including bakery, deli, fresh produce, financial services. Choppies Bakery offers the best bread and pastries of all varieties such as buckwheat bread Sweet bun and more, fruit-filled, sugar-coated, powdered, glazed, and dipped pastries complemented with beverages. The deli department hosts an array of traditional and international foods. Fruit and vegetable departments are traditionally key departments for Choppies.

\section{Pricing Strategy}

Pricing strategies help you choose prices that maximize profits and shareholder value while considering consumer and market demand by stating that pricing strategies take into account many of your business factors, like revenue goals, marketing objectives, target audience, brand positioning, and product attributes. They're also influenced by external factors like consumer demand, competitor pricing, and overall market and economic trends.

\section{Product Positioning Strategy}

According to (Gabriel \& Lang, 2015) your product positioning strategy is one of the most important marketing initiatives you will grapple with when introducing or re-branding goods and services. In a nutshell, product positioning refers to the inherent qualities that distinguish the item you're selling from comparable items marketed by your competitors.

\section{Environmental Analysis (Internal)}

The environmental analysis consists of objectives, vision, mission, and value of the company. An important measure in an internal analysis is to determine your organization's level of strength and competency. A strong organization uses updated technology systems and equipment to accomplish its work.

\section{I0. Competitive Advantage}

- Consistently lowest prices

- Stores close to commuter and residential nodes

- Attractive ranges of popular items at value-for-money prices

- Vertically integrated

- Excellent logistics with in-house distribution and centralized warehousing

- "Reverse logistics" principle - focuses on lowest pricing to end-users

- Economies of scale enabling Choppies to deliver the best value for money for consumers

Our objective is to offer you an assortment of well-priced clothing at good quality and great prices. We aim to have something for you and all your family, all ages and sizes. Choppies facts - Holding Company based in Botswana; 212 stores, Three store formats: Hyper stores; Superstores; Value stores, Seven sub-Saharan African countries, Retail space $308704 \mathrm{~m}^{2}$, Inhouse distribution network, 12 distribution centers, Warehouse space 71 $010 \mathrm{~m}^{2}$, Fleet of 820 commercial vehicles, I5 000+ employees $-98 \%$ indigenous staff in countries of operation, Providing customers with more alternatives - we believe that our customers across Africa are ambitious to improve their standard of living and upscale their shopping experience and us at Choppies work relentlessly to deliver on that promise, Since inception in 1986 Choppies has grown from a single store in Botswana to over 200 stores in growing African markets which provide the ideal springboard for further expansion into neighboring under-serviced markets. Gross margin calculation was done to have an estimate of the difference between total return and variable costs. The analysis is also easily understandable because of its simplicity (Nayeem et al., 2020).

\section{Business Strategy of Choppies}

The strategy of Choppies is both low cost and differentiation. They are constantly looking to reduce costs in every step of the business to offer to the customers the best prices. Their motto is value for your money meaning that they are assuring quality products to their customers. At the same time, they want to be different than the competitors to have a competitive advantage. This sector is competitive and Choppies need to be different to attract the customers and increase the market shares. Choppies have a strong brand name. Their products are all marked with their brand and logo.

\section{Comparison between Choppies and SPAR Botswana}

The differences between Choppies and Spar have been shown in this chapter. They have something in common which is easy to compare with. Both of them are successful companies and have huge popularity in the same industry. However, they own a different business strategy to conduct business performance. Benchmarking in here is aiming at evaluating Choppies's strategic management and learning some experiences to improve their strategy and performance better. 


\section{I3. Business Model}

Retailers further benefit from the merchandising expertise, support services, and benchmarking offered by SPAR, which enables them to offer a range of products at competitive prices. Voluntary trading further equips retailers with the ability to customize their product and service offering to be responsive to their local, niche consumer segment needs and expectations. This unlocks value for both retailers and consumers. To support this value creation, our business model is grounded in SPAR's core business as a wholesaler and distributor of goods. At each point in the value chain, we support close working relationships with key stakeholders to enhance our value proposition. We strive to manage our use of resources and the six capitals of value creation through environmentally and socially sustainable business practices.

\section{I4. SWOT Analysis of SPAR}

\section{I4.I Strengths}

- Strengths of SPAR Group Inc. is the first element of the SWOT matrix. According to (Byrne,2018)

- The geographic presence in different regions can act as one of the major strengths of the organization. It determines the business's reached to the target market and ensures easy accessibility.

- The wide product portfolio can allow the organization to expand the customer base and offset the losses from one product category with benefits obtained from the other.

- The location advantage can improve the competitive positioning of the firm in various ways, such as- lower cost, improved accessibility, or enhanced brand image.

- The well-developed and efficiently integrated IT infrastructure can improve operational efficiency and increase knowledge of the latest market trends.

- Competent and committed human capital can act as a powerful source of competitive advantage, particularly when business is service-oriented.

- Workplace diversity can also act as a major business strength, particularly when the organization intends to operate in the international market.

\section{I4.2 Weakness}

- There are gaps in the product range sold by the company. This lack of choice can give a new competitor a foothold in the market.

- We need more investment in new technologies. Given the scale of expansion and different geographies the company is planning to expand into, SPAR Group, Inc. needs to put more money in technology to integrate the processes across the board. Right now the investment in technologies is not at par with the vision of the company.

\section{I4.3 Opportunities}

- The exponential growth in the population and particularly in the existing or potential customer segments is a great growth opportunity for the business organization.

- The changing customer needs, tastes, and preferences can act as an opportunity if the business organization has good market knowledge.

- The development of new technologies to assist the product/service production and delivery process can be exploited to embed innovation in business operations. The advanced technological integration can decrease costs, improve efficiency, and result in the quick introduction of innovative products.

- Reduction in the interest rates makes the fundraising and financing at lower cost easier for the business organization.

- Customers may start preferring new and creative products/services as a result of changing tastes.

- The emergence of new market segments and new niches provide business and product line expansion opportunities.

- Improvement in the customers- lifestyle and standards mean more consumption on consumer goods and services, and more opportunities to encourage the purchase (Byrne, 2018).

\section{I4.4 Threats}

- Changing consumer buying behavior from an online channel could be a threat to the existing physical infrastructure is a driven supply chain model.

- New technologies developed by the competitor or market disrupt could be a serious threat to the industry in medium to long term future.

- The demand for highly profitable products is seasonal in nature and any unlikely event during the peak season may impact the profitability of the company in the short to medium term. 


\section{I5. Conclusion}

The theme of this research project is to discuss the importance of strategic management. As people know, it is one of the compulsory subjects for business students. Nevertheless, why is it so important to learn the knowledge and how to apply the theory into practice? That is a tough question. Due to the globalization and development of the Internet, it is necessary to know the knowledge about strategic management for a company. To solve this problem and explore the benefits of strategic management, this paper was made / by a case study of Choppies Enterprises. It was a difficult task to analyze the strategy of Choppies because of a lack of experience and information about this enterprise. In the theoretical part, as the strategic management involved vast quantities of information, this project selected the basic concepts concerning the topic to discuss. And the strategic analysis as a crucial part was stressed. Thereby the exhaustive analysis of Choppies was made to illustrate the importance of strategic management and provide a successful experience for more companies. This included the current financial performance of Choppies, the company's mission and objectives, and corporate governance. Besides, the societal trends affecting the company were presented along with SWOT analysis. The strategic analysis of Choppies entailed all aspects of environmental scanning. These included environmental analysis showing how the company is affected by external factors as well as how the company deals with them. Besides, environmental scanning also included the internal analysis showing aspects of the organization and its economy. The strategic analysis came together after analyzing a strategy of another Company-Spar and comparing it to Choppies's. Two companies had remarkable differences but were noticed to be quite similar after all. Based on the comparison of the companies 'strategies and despite the similarities, a conclusion was made that H\&M should learn something from Zara but don't need to afraid of it.

\section{Scope of the Future Research}

When finishing this research it can be found that strategic management has played a significant role in the success of Choppies. In this research project, it only concentrates on a case study of Choppies. Probably it cannot be applied to other companies or fields. However, it can be concluded that every company needs an accurate strategy before they explore the market. They should be clear about the marketing analysis and the advantage, disadvantages, mission, vision, and goals. People can learn some successful experiences from some examples, but can't copy the strategy from others. Since every company has its way of operation and characteristics. The author hopes this research project can help Choppies achieve a better performance soon and it can raise more and more attention to strategic management. There is visionary management where there is the hope of making Botswana a prosperous nation with better living standards, high per capital income as summarized in Vision 2030 of this nation. This could only be achieved when all entities are performing well for the benefit of the nation at large.

\section{Acknowledgment}

I would like to acknowledge the strict and focused guidance I got from my supervisor, Professor Yan Wei. Thank you for sharing your wisdom with me and seeing me through. My heartfelt appreciation and indebtedness also go to my family especially my mum, my brothers for making my dreams come through by giving me moral support all the time. Finally and most importantly, I wish to thank my God and my Creator for bringing me this far.

\section{References}

Byrne. (2018). Does the management has the customer impact on market analysis in choppers in South Africa, Journal of Management, 3(2), 23-32.

Eriksson, P., \& Kovalainen, A. (2008). Qualitative methods in Business research.SAGE Publications Ltd. London, 3(2), 43-45.

Gabriel, Y., \& Lang, T. (2015). The unmanageable consumer.Sage.

Hitt, M. A., Ireland, R. D., \& Hoskisson, R. E. (2012). Strategic management cases: competitiveness and globalization. Cengage Learning.

Jofre, S. (20II). Strategic Management: The theory and practice of strategy in (business) organizations.

Library and Archives in southern Africa (2017).Choppies integrated annual report. Retrieved from https://choppiesgroup.com/wp-content/uploads/2016/05/Choppies-annual-Report_2017-I.pdf

Maramwidze-Merrison, E. (2016). Innovative Methodologies in Qualitative Research: Social Media Window for Accessing Organisational Elites for interviews. Electronic Journal of Business Research Methods, I4(2).

Muriuki, M. W., Ipara, H., \&Kiringe, J. W. (2017). The cost of livestock lost to lions and other wildlife species in the Amboseli ecosystem, Kenya. European journal of wildlife research, 63(4), 60.

Nayeem, A. R., Islam, M. S., \& Akter, M. F. (2020).The Influencing Factors of Brand Equity on Consumer Purchase Intention of Cell Phones in Bangladesh.GSJ, 8(I).

Nayeem, A.R. (2018).Halal Food Awareness of Young Adult Muslim Consumer's: Comparative Study between Bangladesh and Philippines, Global Journal of Management and Business Research: E-Marketing, I8(7), I.0.

Shawon, S. S., Hasan, M. A., Nayeem, A. R., \& Uddin, M. B. (2018).Online Purchasing Behavior among Bangladeshi Young Generation: Influencing Factors and Impact. Asian Business Review, 8(3), 17-I28. 
Verweire, K. (2018). The challenges of implementing strategy. Journal of Strategic Management, 8(2), I23.

\section{Copyrights}

Copyright for this article is retained by the author(s), with first publication rights granted to the journal.

This is an open-access article distributed under the terms and conditions of the Creative Commons Attribution license (http://creativecommons.org/licenses/by/4.0/) 